\title{
Solid-state stability study of meropenem - solutions based on spectrophotometric analysis
}

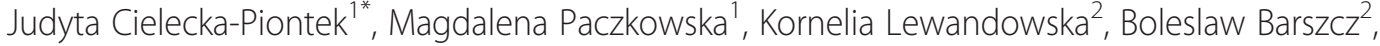 \\ Przemyslaw Zalewski ${ }^{1}$ and Piotr Garbacki
}

\begin{abstract}
Background: B-Lactam antibiotics are still the most common group of chemotherapeutic drugs that are used in the treatment of bacterial infections. However, due to their chemical instability the potential to apply them as oral pharmacotherapeutics is often limited and so it is vital to employ suitable non-destructive analytical methods. Hence, in order to analyze such labile drugs as $\beta$-lactam analogs, the application of rapid and reliable analytical techniques which do not require transferring to solutions or using organic solvents, following the current green approach to pharmaceutical analysis, is necessary. The main objective of the present research was to develop analytical methods for the evaluation of changes in meropenem in the solid state during a stability study.

Results: The UV, FT-IR and Raman spectra of meropenem were recorded during a solid-state stability study. The optimum molecular geometry, harmonic vibrational frequencies, infrared intensities and Raman scattering activities were calculated according to the density-functional theory (DFT/B3LYP method) with a $6-31 \mathrm{G}(\mathrm{d}, \mathrm{p})$ basis set. As the differences between the observed and scaled wavenumber values were small, a detailed interpretation of the FT-IR and Raman spectra was possible for non-degraded and degraded samples of meropenem. The problem of the overlapping spectra of meropenem and ring-containing degradation products was solved by measuring changes in the values of the first-derivative amplitudes of the zero-order spectra of aqueous solutions of meropenem. Also, molecular electrostatic potential (MEP), front molecular orbitals (FMOs) and the gap potential between highest occupied molecular orbital (HOMO) and lowest unoccupied molecular orbital (LUMO) were determined.

Conclusions: Based on the findings of this work, it appears possible to use time-saving and reliable spectrophotometric analytical methods, supported by quantum-chemical calculations, for solid-state stability investigations of meropenem. The methods developed for this study may be considered a novel, green solution to pharmaceutical analysis of labile drugs - an alternative for the recommended chromatographic procedures.
\end{abstract}

Keywords: Meropenem, Derivative spectroscopy, FT-IR spectroscopy, Raman-spectroscopy, Degradation, Solid state

\section{Background}

The chemical instability of drugs may reduce pharmacotherapeutic possibilities and affect the selection criteria when deciding on analytical methods for the quality control of labile medicines. In that group of drugs, the problem of the susceptibility of $\beta$-lactam antibiotics to degradation in solutions and in the solid state has often been reported [1-3]. Since oral administration of antibiotics is not possible in the case of some $\beta$ lactam analogs, the remaining solution is the parenteral

\footnotetext{
* Correspondence: jpiontek@ump.edu.pl

${ }^{1}$ Department of Pharmaceutical Chemistry, Faculty of Pharmacy, Poznan University of Medical Sciences, Grunwaldzka 6, Poznań 60-780, Poland Full list of author information is available at the end of the article
}

route, which involves the risk of unwanted side effects $[4,5]$. In view of the significant lability of $\beta$-lactam analogs, the application of suitable analytical methods is of utmost importance. The quality control of drugs in the solid state is expected to rely on methods ensuring minimization of sample transformation, for example elimination of sample derivatization or limitation of reactions with chemical reagents. As it has been established, organic solvents affect the rate of degradation of $\beta$-lactam antibiotics as well as the formation of degradation products [6-8]. Therefore, the methodology of studying $\beta$-lactam antibiotics in solutions is required to eliminate such reagents that provide inconsistent environments.

\section{Chemistry Central}


Among the $\beta$-lactam antibiotics, carbapenems are analogs that are especially susceptible to enzymatic and chemical degradation [9]. Meropenem is a carbapenem analog in which the introduction of a methyl group at C4 solved the problem of enzymatic instability (Figure 1). What still needs a solution is the lack of chemical stability of meropenem, a problem which may be addressed by finding control methods ensuring therapeutic safety and effectiveness [10,11]. Meropenem is the first methylcarbapenem analog introduced into therapeutic use $[12,13]$ characterized by activity against a wide range of Gram-negative and Gram-positive aerobic and anaerobic bacteria $[14,15]$. Recent studies proved meropenem to be especially efficient in the treatment of tuberculosis, caused by Mycobacterium tuberculosis, after connection with clavulanic acid, an inhibitor of $\beta$-lactamases $[16,17]$.

Therefore, in light of the therapeutic potential of meropenem, including its bactericidal activity against resistant strains, it is vital to develop methods of quality control able to take into account its significant susceptibility to degradation. Meropenem is known to be very unstable in aqueous solutions and in the solid state [18]. Depending on affecting factors and the form of meropenem, different degradants are formed. For example, during the degradation of meropenem in acidic solutions degradation products with an open $\beta$-lactam ring are formed whereas thermal degradation of meropenem leads to the formation of 4-methyl-3- $(1 \mathrm{H}-$ pyrrol-3-ylsulfanyl)-5H-pyrrole-2-carboxylic acid. Mendez et al. suggested that the modification of the side chain of meropenem in the direction of a pyrrolic-ring degradation product is a result of decarboxylation and aromatization of the pyrrolidine ring and hydrolysis of the $\beta$-lactam ring, considered an intermediate stage of degradation $[19,20]$. Also, it was observed that during solid-state stability studies of carbapenem analogs different degradants were formed during thermolysis as a consequence of the highly strained fused ring system [21,22].

The most common techniques for the determination of meropenem during stability studies are based on chromatography. Due to the insolubility of carbapenems in organic solvents, only reversed-phase (RP) liquid chromatography is used in the analysis of meropenem [23]. Since the degradation of $\beta$-lactam analogs is known to be additionally affected by solvolysis, it appears justified to eliminate the use of organic solvents [24]. Therefore, in order to ensure the reliability of determination, it is vital to use such analytical methods that do not require the application of organic solvents or the placement of samples in media other than target intravenous solutions during studies of meropenem in the solid state. The analytical procedures that overcome those problems are spectral methods. They allow a rapid analysis of meropenem in the solid state (FT-IR, Raman spectroscopy) and in aqueous solutions, relying exclusively on dissolution in water samples (UV). For the determination of carbapenems, including meropenem, only firstderivative, first-derivative spectrum ratio and thirdderivative UV spectroscopies were used, which permitted eliminating interferences originating from degradation products with an open $\beta$-lactam ring and dimers $[20,25,26]$ formed in aqueous solutions. A literature review has not demonstrated the use of spectroscopic methods as an alternative mode of quality control of meropenem in the solid state.

The main objective of the present study was to develop and apply spectrophotometric methods for the quality control of meropenem in the solid state, which involved investigating vibrations within the bonds in a meropenem molecule and their changes during degradation by using spectral methods (FT-IR, Raman spectroscopy) on the basis of chemical-quantum calculations and developing a selective analytical method for the determination of changes in meropenem concentrations in the solid state with the use of water instead of organic solvents.

\section{Experimental}

\section{Substances and spectroscopic measurements}

The meropenem reference standards (purity $>98 \%$ ) were supplied by Pharmachem International Co., (China). The commercial preparation of meropenem, Meronem ${ }^{\circ}$, contained meropenem $500 \mathrm{mg}$ and sodium carbonate $140 \mathrm{mg}$.

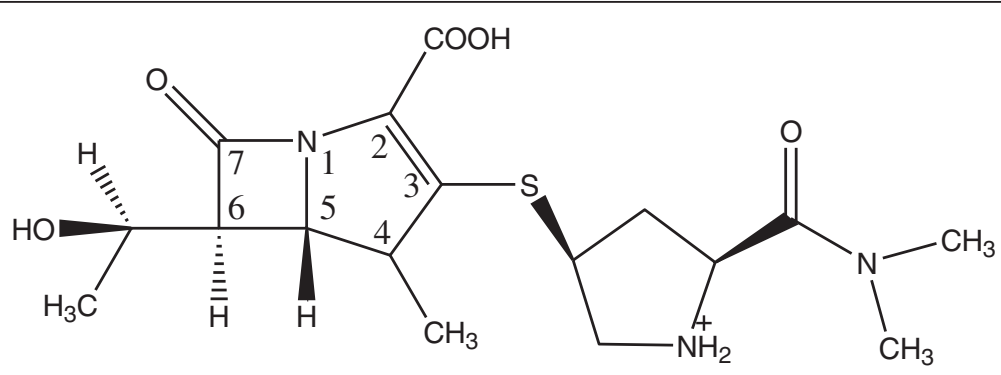

Figure 1 Chemical strucutre of meropenem. 
The first derivatives of ultraviolet spectra of meropenem were recorded by using a UV-VIS Lambda 20 (PerkinElmer) spectrophotometer equipped with $1.0 \mathrm{~cm}$ in-width quartz cells and controlled via the UV WinLab software. Water was used as solvent. The vibrational infrared spectra of meropenem were recorded between 400 and $7000 \mathrm{~cm}^{-1}$ in powder, at room temperature, with an FT-IR Bruker Equinox 55 spectrometer equipped with a Bruker Hyperion 1000 microscope. The Raman scattering spectra were obtained with a LabRAM HR800 spectrometer (Horiba Jobin Yvon) with laser excitation $\lambda_{\text {exc }}=$ $633 \mathrm{~nm}$ (He-Ne laser). In each case the power of the laser beam at the sample was less than $1 \mathrm{~mW}$ to avoid damaging the sample. High quality pure water was prepared using an Exil SA 67120 purification system (Millipore).

\section{Stability studies}

For stability studies, $5 \mathrm{mg}$ samples of meropenem were weighed into $5 \mathrm{ml}$ vials. To evaluate their stability at increased air humidity, they were placed in heat chambers at $313 \mathrm{~K}$ in desiccators containing saturated solutions of sodium chloride (relative humidity $(\mathrm{RH}) \approx 76.4 \%$ ). The changes of meropenem concentration were studied after $15 ; 30 ; 45 ; 60 ; 75 ; 90 ; 105$ and 120 minutes of degradation. To evaluate the stability of meropenem in dry air, the vials were immersed in a sand bath placed in heat chambers at $323 \mathrm{~K}$. The sand was first dried, and then kept at $323 \mathrm{~K}$ with preventing the absorption of water vapor from the environment. The changes of meropenem concentration were studied after $2.5 ; 5 ; 7.5 ; 10 ; 12.5 ; 15$; 17.5; and 20 hours of degradation.

The UV method was validated according to the International Conference on Harmonization Guidelines [27] in terms of linearity, precision, accuracy, and limits of detection and quantitation for meropenem were established.

\section{Theoretical calculations}

The derivative spectrophotometric method was based on the transformation of the zero-order spectrum of meropenem into its first derivative $(\Delta \mathrm{A} / \Delta \lambda)$ by using the UV WinLab software. In order to interpret the experimental results of IR absorption and Raman scattering, quantum-chemical calculations were performed by using the Gaussian 03 package [28]. The GaussView software was utilized to propose the initial geometry of the investigated molecules and to visually inspect the normal modes. The molecular geometries were optimized by means of a density functional theory (DFT) method with the B3LYP hybrid functional and a 6-31G(d,p) basis set.

\section{Results and discussion}

The FT-IR and Raman spectra of non-degraded and degraded samples of meropenem obtained in this study allowed characterization of molecular vibrations as well as changes in its structure resulting from degradation during storage in the solid state. The calculated IR and Raman scattering spectra, obtained by means of the density functional theory, were used as reference. The application of the first derivative of the zero-order UV spectra permitted determination of meropenem in the presence of 4-methyl-3-(1H-pyrrol-3-ylsulfanyl)-5H-pyrrole-2-carboxylic acid, which is a degradation product that can form under the recommended storage conditions for meropenem preparations [20]. Additionally, the FMOs and the MEP of meropenem were determined based on quantum-chemical calculations. The following sections discuss spectral analysis and the findings of theoretical calculations.

\section{Vibrational assignments}

A number of bands corresponding to the vibrations of the $\beta$-lactam and pyrrolidine 4:5 bicyclic fused rings and of certain substituents were identified in the IR absorption and Raman scattering spectra of meropenem. Let us start with the bands located at 653 and $690 \mathrm{~cm}^{-1}$. These modes also contained components corresponding to the bending vibrations of the $\mathrm{C}-\mathrm{O}-\mathrm{H}$ bond in a carboxyl group. In the experimental IR spectra they were located at 668 and $705 \mathrm{~cm}^{-1}$. The bands corresponding to the bending vibrations of the carboxyl group $\mathrm{C}-\mathrm{O}-\mathrm{H}$ bond were also observed at 771 and $768 \mathrm{~cm}^{-1}$ in the calculated and experimental IR spectra, respectively. The bending vibrations of the $\mathrm{C}-\mathrm{O}-\mathrm{H}$ bond were observed at 1202 and $1188 \mathrm{~cm}^{-1}$ (calculated and experimental IR and Raman spectra, respectively), too. This mode also showed components corresponding to the stretching vibration of the $\mathrm{C}-\mathrm{N}$ bond in the $\beta$-lactam ring. The bands related to the stretching vibrations of the $\mathrm{C}-\mathrm{N}$ bond in the $\beta$-lactam ring were also observed in the calculated spectra at 1135 and $1417 \mathrm{~cm}^{-1}$. In the experimental spectra, they were located at 1143 and $1388 / 1391 \mathrm{~cm}^{-1}$ (IR/Raman, respectively). The band at $1135 \mathrm{~cm}^{-1}$ was corresponding also to the wagging and twisting vibrations of the $\mathrm{C}-\mathrm{H}$ bonds present in the entire structure. The band at $1417 \mathrm{~cm}^{-1}$ was complex and composed of many normal modes of vibrations. This mode had additional components corresponding to the stretching vibrations of the $\mathrm{C}-\mathrm{C}$ bond between the pyrrolidine ring and the carboxyl group and to the scissoring vibrations of the $\mathrm{C}-\mathrm{H}$ bond in the methyl group in the trans-hydroxyethyl group at $\mathrm{C} 2$. The band related to the stretching vibrations of the $\mathrm{C}-\mathrm{C}$ bond in the $\beta$ lactam ring was also observed at $994 / 989 \mathrm{~cm}^{-1}$ in the calculated/experimental Raman scattering spectra. The range $1600-1900 \mathrm{~cm}^{-1}$ in the calculated spectra exhibited distinct bands related to the stretching vibrations of the $\mathrm{C}=\mathrm{C}$ and $\mathrm{C}=\mathrm{O}$ bonds. The band associated with the stretching of the $\mathrm{C}=\mathrm{C}$ bond in the $\beta$-lactam and pyrrolidine $4: 5 \mathrm{bi}$ cyclic fused rings was located in the calculated spectra at 
$1616 \mathrm{~cm}^{-1}$. In the experimental spectra, they were observed at 1549 and $1553 \mathrm{~cm}^{-1}$ in the IR and Raman spectra, respectively. The stretching vibrations of the $\mathrm{C}=\mathrm{O}$ bond in the $\beta$-lactam ring were located at $1887 / 1749 \mathrm{~cm}^{-1}$ (calculated/experimental IR spectra). Lower wavenumbers in the calculated spectra (1751 and $1818 \mathrm{~cm}^{-1}$ ) revealed bands corresponding also to the stretching vibrations of the $\mathrm{C}=\mathrm{O}$ bonds but in the trans-hydroxyethyl and carboxyl substituents. In the experimental IR spectra a split was observed into those bands and bands related to the vibrations at 1749, 1604 and $1651 \mathrm{~cm}^{-1}$, which resulted from the fact that the bonds located in the external part of meropenem molecules were likely to be affected by intermolecular interaction. Fairly distinct bands related to the breathing of the pyrrolidine ring at $695 / 715 \mathrm{~cm}^{-1}$ in the calculated/experimental IR spectra were located. That mode also contained components related to the bending vibrations of the $\mathrm{C}=\mathrm{O}$ bond in the dimethylcarbamoyl group situated closest to the pyrrolidine ring. A band corresponding to the breathing of the pyrrolidine ring was identified in the theoretic Raman spectrum at $784 \mathrm{~cm}^{-1}$. In contrast, the stretching vibrations of the $\mathrm{C}-\mathrm{N}$ bond between the nitrogen atom and the methyl groups in the dimethylcarbamoyl substituents in the experimental spectra were shifted to $810 \mathrm{~cm}^{-1}$. A greater band shift was observed for the bands located in the calculated Raman spectra at $991 \mathrm{~cm}^{-1}$, which was related to the stretching vibrations of the $\mathrm{C}-\mathrm{C}$ bond of the $\beta$-lactam ring, especially between the carbonyl group and the $\mathrm{C}-\mathrm{N}$ bond in that ring whereas between the nitrogen atom and the methyl group in the dimethylcarbamoyl substituents the stretching vibrations of the $\mathrm{C}-\mathrm{N}$ bond were identified at $1289 \mathrm{~cm}^{-1}$ in the calculated spectra. In the experimental IR/Raman those bands were located at $1265 / 1263 \mathrm{~cm}^{-1}$. The stretching vibrations of the $\mathrm{C}-\mathrm{N}$ bond in the dimethylcarbamoyl substituents were also observed at $1430 / 1388 \mathrm{~cm}^{-1}$ in the calculated/experimental IR spectra. Fairly distinct bands associated with the stretching vibrations of the $\mathrm{C}-\mathrm{C}$ bond in the pyrrolidine ring as well as the wagging and twisting vibrations of the $\mathrm{C}-\mathrm{H}$ bonds at the $\beta$-lactam ring were located at $1049 \mathrm{~cm}^{-1}$ in the calculated and at $1056 \mathrm{~cm}^{-1}$ in the experimental spectrum. The band corresponding to the stretching of the $\mathrm{C}-\mathrm{C}$ bond present in the $\beta$-lactam and pyrrolidine 4:5 bicyclic fused rings and between the carbon atom in the carboxyl group was observed at $1330 / 1307 \mathrm{~cm}^{-1}$ in the calculated/experimental Raman spectra. Clearly visible bending vibrations of the $\mathrm{O}-\mathrm{H}$ bonds in the carboxyl group were observed at $575 / 603$ and $635 / 668 \mathrm{~cm}^{-1}$ in the calculated/experimental spectra, respectively. Many bands corresponding to the vibrations of the $\mathrm{C}-\mathrm{H}$ bonds in the alkali substituents were found in the Raman and IR spectra. The bands related to the wagging and twisting vibrations of the $\mathrm{C}-\mathrm{H}$ bonds in the trans-hydroxyethyl group and in the $\beta$-lactam and

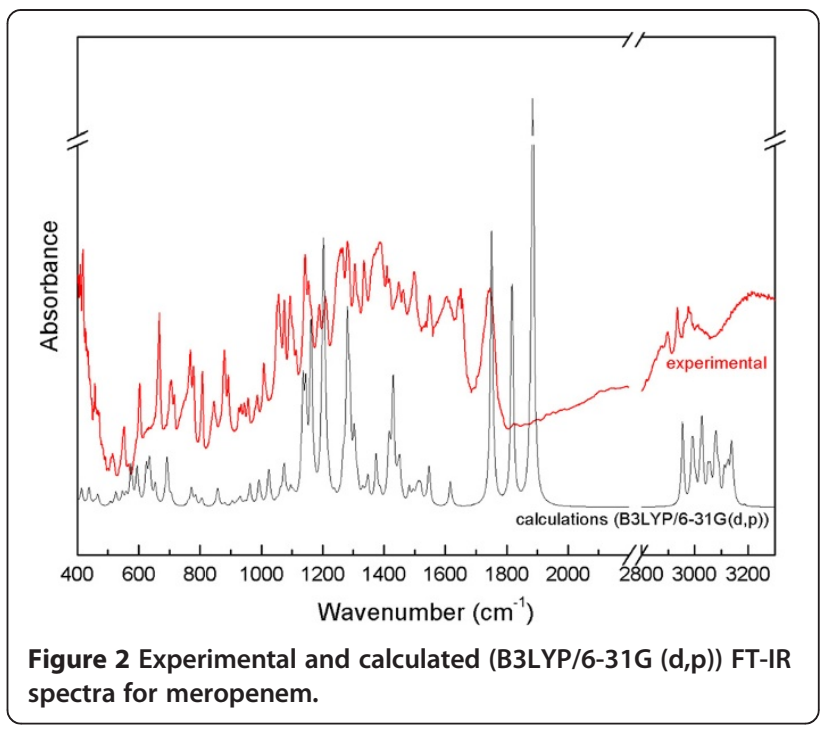

pyrrolidine 4:5 bicyclic fused rings were located in the experimental IR spectrum at 1075 and $1335 \mathrm{~cm}^{-1}$. The stretching vibration of the $\mathrm{C}-\mathrm{H}$ bonds in that group occurred at 2961 and $2997 \mathrm{~cm}^{-1}$ in the experimental Raman scattering spectrum. A band associated with the stretching vibrations of the $\mathrm{C}-\mathrm{H}$ bonds in the dimethylcarbamoyl group was identified at $2900 \mathrm{~cm}^{-1}$. In the IR and Raman scattering spectra, bands related to the scissoring and wagging vibrations of the $\mathrm{C}$ - $\mathrm{H}$ bonds in the dimethylcarbamoyl group were located between $1440-1500 \mathrm{~cm}^{-1}$. Bands corresponding to the twisting vibrations of the $\mathrm{C}-\mathrm{H}$ bonds in the same part of the molecule were observed at $1143 / 1147 \mathrm{~cm}^{-1}$ in the calculated/experimental Raman spectra and at $1160 / 1153 \mathrm{~cm}^{-1}$ in the calculated/experimental IR spectra. Figures 2 and 3 present the experimental and calculated infrared and Raman scattering spectra

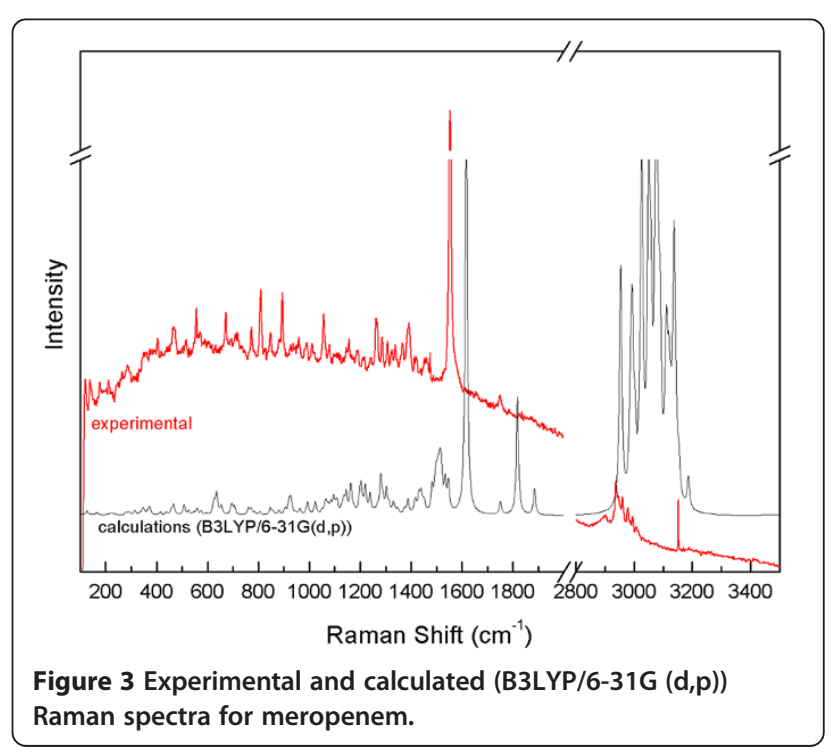


of meropenem, respectively - the most important of which are listed in Table 1.

The next stage of this work was aimed at evaluating the suitability of FT-IR and Raman spectroscopies for the assessment of changes in the structure of meropenem as a consequence of exposure to temperature and humidity. The degradation of meropenem at increased relative air humidity (simulation of storage in a damaged container) and at increased temperature at $\mathrm{RH}=0 \%$ (simulation of storage in an airtight container) was analyzed during a stability study $(\mathrm{RH} \approx 76.4 \%, \mathrm{~T}=313 \mathrm{~K}, \mathrm{t}=1.0 \mathrm{~h}$ and $\mathrm{RH}=0 \%$, $\mathrm{T}=323 \mathrm{~K}, \mathrm{t}=5.0 \mathrm{~h}$ ). It was found that by analyzing the FT-IR spectra of meropenem it was possible to assess changes in the structure of its samples at increased temperature, at $\mathrm{RH}=0 \%$. Based on a comparison of the spectra of non-degraded samples, using chemical-quantum

Table 1 Comparison of observed and calculated vibrational modes of meropenem before degradation

\begin{tabular}{|c|c|c|}
\hline IR calc/exp & Raman calc/exp & Band assignment \\
\hline \multicolumn{2}{|c|}{ Wavenumber $\left(\mathrm{cm}^{-1}\right)$} & \\
\hline $575 / 603$ & & $\mathrm{O}-\mathrm{H} b$ in carboxylic group \\
\hline $635 / 668$ & & $\mathrm{O}-\mathrm{H} b$ in carboxylic group \\
\hline $653 / 668$ & & def. pyrrolidine ring $+\mathrm{C}-\mathrm{O}-\mathrm{H} b$ in carboxyl group \\
\hline $690 / 705$ & & def. pyrrolidine ring $+\mathrm{C}-\mathrm{O}-\mathrm{H} b$ in carboxyl group \\
\hline $695 / 715$ & & breathing $\beta$-lactam ring $+\mathrm{C}=\mathrm{O} b$ in dimethylcarbomoyl group \\
\hline \multirow[t]{4}{*}{ 771/768 } & & carbonyl group $b$ in carboxylic group \\
\hline & $784 / 810$ & breathing $\beta$-lactam ring $+\mathrm{C}-\mathrm{N} s$ between $\mathrm{N}$ and methyl group in dimethylcarbomoyl group \\
\hline & $991 / 959$ & $\mathrm{C}-\mathrm{C}$ between $\beta$-lactam and dimethylcarbomoyl group $+\mathrm{C}-\mathrm{N}$ in $\beta$-lactam \\
\hline & $994 / 989$ & $\mathrm{C}-\mathrm{C} s$ in basis ring $+\mathrm{CH}_{3}$ w at pyrrolidine ring \\
\hline 1049/1056 & $1049 / 1056$ & $\mathrm{C}-\mathrm{C}$ in $\beta$-lactam ring $+\mathrm{CH}$ t/w in trans-hydroxyethyl group \\
\hline 1074/1075 & & $\mathrm{CH} t / w$ in trans-hydroxyethyl group \\
\hline \multirow[t]{2}{*}{$1135 / 1143$} & & $\mathrm{CH} t / W+\mathrm{C}-\mathrm{N} s$ in pyrrolidine ring \\
\hline & $1143 / 1147$ & $\mathrm{CH}_{2} t$ and methyl $t$ in dimethylcarbomoyl group \\
\hline $1160 / 1153$ & & $\mathrm{CH} t$ in $\mathrm{CH}_{2}$ and methyl group in dimethylcarbomoyl group \\
\hline \multirow[t]{2}{*}{$1202 / 1188$} & 1202/1188 & $\mathrm{C}-\mathrm{N} s$ in pyrrolidine ring $+\mathrm{C}-\mathrm{O}-\mathrm{H} b$ in carboxyl group \\
\hline & $1221 / 1210$ & $\mathrm{C}-\mathrm{H} w$ at $\beta$-lactam ring \\
\hline \multirow[t]{2}{*}{$1289 / 1265$} & $1289 / 1263$ & $\mathrm{C}-\mathrm{N} s$ at $4 \mathrm{CH}_{3}+\mathrm{C}-\mathrm{H} w$ \\
\hline & $1330 / 1307$ & $\mathrm{C}-\mathrm{C} s$ between pyrrolidine ring and $\mathrm{C}$ at $\mathrm{COH}$ group \\
\hline $1375 / 1335$ & & $\mathrm{C}-\mathrm{H}$ w in $\mathrm{CH}$ in trans-hydroxyethyl group $+\mathrm{CH} w$ in pyrrolidine ring \\
\hline $1417 / 1388$ & $1417 / 1391$ & $\begin{array}{l}\mathrm{C}-\mathrm{C} s \text { between carboxyl group and pyrrolidine ring }+\mathrm{C}-\mathrm{N} s \text { in basis ring }+\mathrm{C}-\mathrm{H} s \mathrm{C} \text { in } \mathrm{CH}_{3} \\
\text { in trans-hydroxyethyl group and methyl group }\end{array}$ \\
\hline \multirow[t]{4}{*}{$1430 / 1388$} & & $\mathrm{C}-\mathrm{N} s$ between $\mathrm{CO}$ and $\mathrm{CH}_{3}$ in dimethylcarbomoyl group \\
\hline & $1438 / 1421$ & $\mathrm{C}-\mathrm{H}$ sc in dimethylcarbomoyl group \\
\hline & $1482 / 1459$ & $\mathrm{C}-\mathrm{H}$ w in dimethylcarbomoyl group \\
\hline & $1513 / 1466$ & $\mathrm{C}-\mathrm{H} s$ \\
\hline $1519 / 1448$ & & $\mathrm{CH} 3$ w/sc in dimethylcarbomoyl group \\
\hline $1548 / 1500$ & & $\mathrm{CH} 3 \mathrm{w} / \mathrm{sc}$ in dimethylcarbomoyl group \\
\hline $1616 / 1549$ & $1616 / 1553$ & $\mathrm{C}=\mathrm{C} s$ in pyrrolidine ring \\
\hline 1751/1749, 1604 & & $\mathrm{C}=\mathrm{O} s$ in trans-hydroxyethyl group \\
\hline 1818/1749, 1651 & 1818/1749 & $\mathrm{C}=\mathrm{O} \mathrm{s}$ in carboxyl group \\
\hline \multirow[t]{5}{*}{$1887 / 1749$} & & $\mathrm{C}=\mathrm{O} \mathrm{s}$ in pyrrolidine ring \\
\hline & $3020 / 2939$ & $\mathrm{C}-\mathrm{H} s$ in dimethylcarbomoyl group \\
\hline & $3027 / 2947$ & $\mathrm{C}-\mathrm{H} s$ in dimethylcarbomoyl group \\
\hline & $3052 / 2961$ & $\mathrm{C}-\mathrm{H} s$ in trans-hydroxyethyl group group \\
\hline & $3137 / 2997$ & $\mathrm{C}-\mathrm{H} \mathrm{s}$ in methyl group \\
\hline
\end{tabular}

Vibrational modes: $s$ stretching, $b$ bending, $w$ wagging, sc scissoring, $r$ rocking, $\mathrm{t}$ twisting. 
calculations to identify vibrations, the most distinct alterations were observed in the ranges $660-700 \mathrm{~cm}^{-1}, 850-$ $900 \mathrm{~cm}^{-1}$, and $1350-1800 \mathrm{~cm}^{-1}$ (Figure 4). Regarding changes in the molecular structure of meropenem associated with the cleveage of bonds in the structure of the $\beta$-lactam and pyrrolidine 4:5 bicyclic fused rings, their manifestations included an increase in band intensity at $879 \mathrm{~cm}^{-1}$, changes in the shapes of the bands and in the
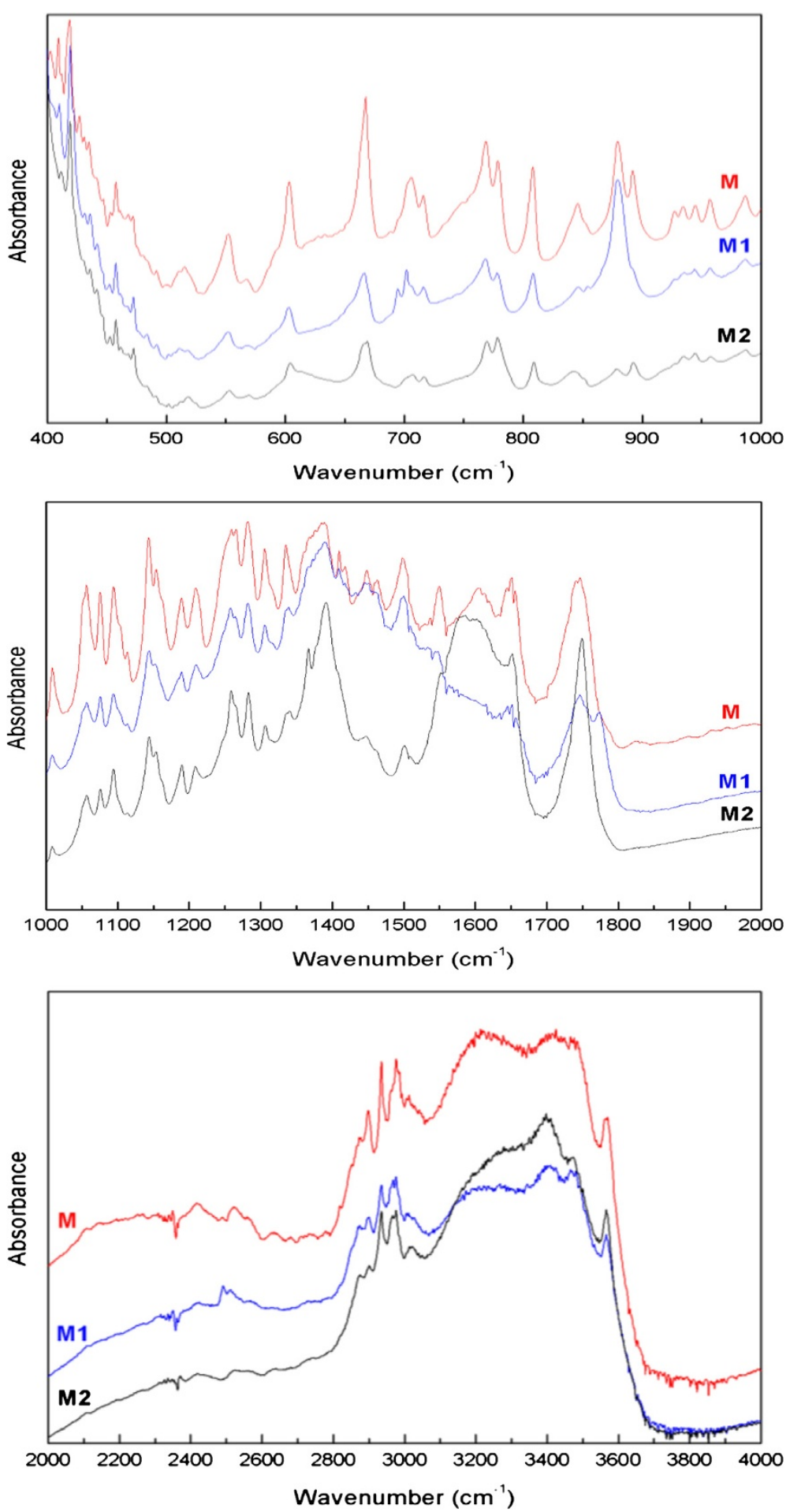

Figure 4 Experimental FT-IR spectra for non-degraded and degraded meropenem ( $M$ - non-degraded sample; $M_{1}$ - degraded samples at $50^{\circ} \mathrm{C}, \mathrm{RH}=0 \%, \mathrm{t}=5 \mathrm{~h} ; \mathrm{M}_{2}$ - degraded samples at $40^{\circ} \mathrm{C}, \mathrm{RH}=76.5 \%, \mathrm{t}=1 \mathrm{~h}$ ). 


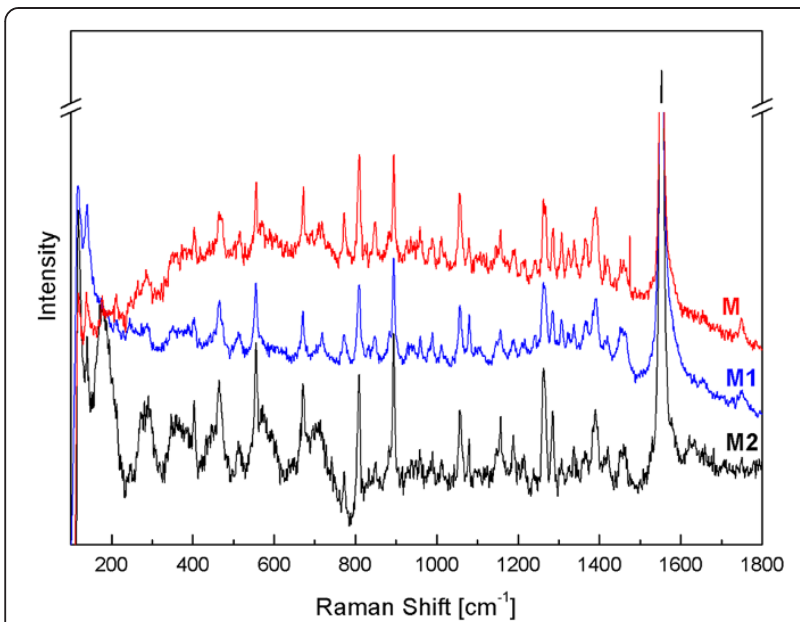

Figure 5 Experimental Raman spectra for non-degraded and degraded meropenem ( $M$ - non-degraded sample; $M_{1}$ - degraded samples at $50^{\circ} \mathrm{C}, \mathrm{RH}=0 \%, \mathrm{t}=5 \mathrm{~h} ; \mathrm{M}_{2}$ - degraded samples at $40^{\circ} \mathrm{C}, \mathrm{RH}=76.5 \%, \mathrm{t}=1 \mathrm{~h}$ ).

ratios of the intensities between the bands in the range $1350-1800 \mathrm{~cm}^{-1}$, changes in the band at $1749 \mathrm{~cm}^{-1}$ corresponding to the stretching vibrations of the $\mathrm{C}=\mathrm{O}$ bond in the $\beta$-lactam ring as well as the occurrence of a band at $695 \mathrm{~cm}^{-1}$ in samples degraded at $\mathrm{T}=323 \mathrm{~K}, \mathrm{RH}=0 \%$. The changes at $1500-1600 \mathrm{~cm}^{-1}$ could be explained by the formation of a new bond between the nitrogen and the hydrogen atoms in the pyrrolidine ring. Also, the intraand inter-molecular impact of the open $\beta$-lactam ring might be responsible for the degradation process.

By analyzing changes in the FT-IR spectra of meropenem exposed to increased relative air humidity $\left(\mathrm{RH}=76.4 \%, \mathrm{~T}=40^{\circ} \mathrm{C}\right)$ it was possible to determine a cleavage of the $\beta$-lactam ring. The observed changes were not characteristic and were expressed by the appearance of bands at 1747 and $1748 \mathrm{~cm}^{-1}$ at increased temperature and $\mathrm{RH}=0 \%$ and at increased relative air humidity, respectively.

The identification and evaluation of qualitative changes in meropenem that may occur during storage in commercial packaging based on analyzing the FT-IR spectra of that carbapenem analog may be considered a timeefficient, cost-effective and reliable analytical tool.

The identification of meropenem based on the analysis of Raman spectra may be recommended as an alternative method but only for non-degraded samples as the vibration bands of degradation products are not sufficiently distinct in Raman spectra, probably due to the fact meropenem contains covalently polarized bonds (Figure 5).

\section{UV spectral studies}

The zero-order absorption spectra of meropenem and of its solid-state degradation products overlapped whereas their first-derivative spectra permitted elimination of that problem. As a result of applying derivative spectrophotometry, the linear differences in the values of peak amplitudes of meropenem (at a zero-crossing wavelength of $307 \mathrm{~nm}$ ) in response to changes in the concentration of meropenem were determined (Figure 6). In the firstderivative spectra of degraded samples of meropenem under the influence of increased temperature in dry air, a bathochromic effect was observed. A shift of bands in the UV spectrum related to the formation of degradants was also observed when evaluating changes in the FT-IR spectra of samples of degraded meropenem under the same conditions. Elragehy et al. reported application of UV spectroscopy for the determination of meropenem in the presence of degradation products formed in solutions. The problem of overlapping open-ring degradation products as the main degradants was solved by employing first-derivative, first-derivative spectrum ratio and bivariate analyses. The hypsochromic effect of zero-order spectra was reported [20].

By achieving the desired selectivity of determination of meropenem after applying first-derivative spectrophotometry, it was possible to analyze it quantitatively. The calibration curve was described by the equation $\mathrm{y}=$ $(111,30 \pm 2,27) \times(\lambda=320 \mathrm{~nm})$. The $b$ values calculated from the equation $\mathrm{y}=a \mathrm{x}+b$ were not significant. A
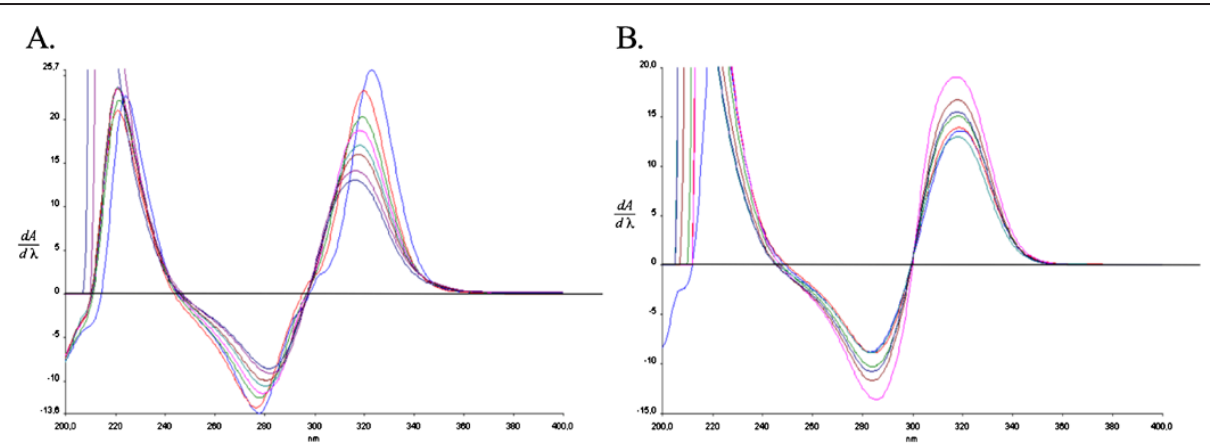

Figure 6 First-derivative spectra of meropenem during degradation in dry air at $\mathrm{T}=50^{\circ} \mathrm{C}, \mathrm{t}=0 ; 2.5 ; 3.0 ; 7.5 ; 10.0 ; 12.5 ; 15.0 ; 17.5 ; 20 \mathrm{~h}$ ) (A) and at increased relative humidity at $\mathrm{RH}=76.5 \%, \mathrm{~T}=40^{\circ} \mathrm{C}, \mathrm{t}=0 ; 15 ; 30 ; 45 ; 60 ; 75 ; 90 ; 105 ; 120 \mathrm{~min}$ (B). 
good intra-day repeatability was determined (1.64\%$2.29 \%$ ) for the three levels (80\%, $100 \%$ and $120 \%$ ) of nominal concentration of meropenem in the linearity range 25-131 $\mu \mathrm{g} / \mathrm{mL}$. Inter-day repeatability also had acceptable values. The percentage recovery of meropenem ranged from $99.9 \%$ to $101.3 \%$ in a pharmaceutical dosage form. The limits of detection and quantitation, describing the smallest concentration of an analyte that can be reliably measured by an analytical procedure, were $3.58 \mu \mathrm{g} / \mathrm{mL}$ and $11.0 \mu \mathrm{g} / \mathrm{mL}$, respectively.

The application of first-derivative spectrophotometry for the determination of meropenem may be a solution to the problem of overlapping bands. The achievement of required validation parameters and the advantages of spectrophotometric determination of meropenem make this method suitable for a routine analysis of that carbapenem analog, allowing its determination in the presence of solid-state degradation products.

\section{DFT studies}

The analysis of the optimized geometry of meropenem indicated that the intraring stress is a result of the fusion of the heterocyclic moieties with the substituents, which can be spatial obstacles to each other. Such molecular configuration of meropenem ensures its binding with PBP (penicillin-binding protein) enzymes that is responsible for antibacterial activity. At the same time that configuration determines the significant susceptibility to degradation of meropenem under the conditions of acid-base hydrolysis and in the presence of oxidizing factors as well as during thermolysis.

The localization of charge density on the frontier molecular orbitals, calculated with the B3LYP hybrid functional and a 6-31G(d,p) basis set, demonstrates a similar localization for the lowest unoccupied molecular orbital and the highest occupied molecular orbital. For both the HOMO and LUMO, the charge density was localized on the $\beta$-lactam and pyrrolidine 4:5 bicyclic fused rings and the carboxylic and carbonyl groups (Figure 7). Since the FMOs are the main orbitals involved in reactivity, the 4:5 bicyclic fused rings of meropenem may be proposed as the main areas where acceptor-donor electron reactions occur. The low value of HOMO-LUMO gap energy for meropenem $(4.25 \mathrm{eV})$ confirms its significant susceptibility to degradation.

In order to predict reactive sites for electrophilic and nucleophilic attack in meropenem, the MEP was also established (Figure 8). The different values of electrostatic potential on the surface are represented by colors. The positive (blue) regions of MEP show electrophilic while the negative (red) areas nucleophilic reactivity. In meropenem, the most pronounced are the negative regions, localized on the carboxylic and carbonyl groups, that indicate possible sites for nucleophilic activity.

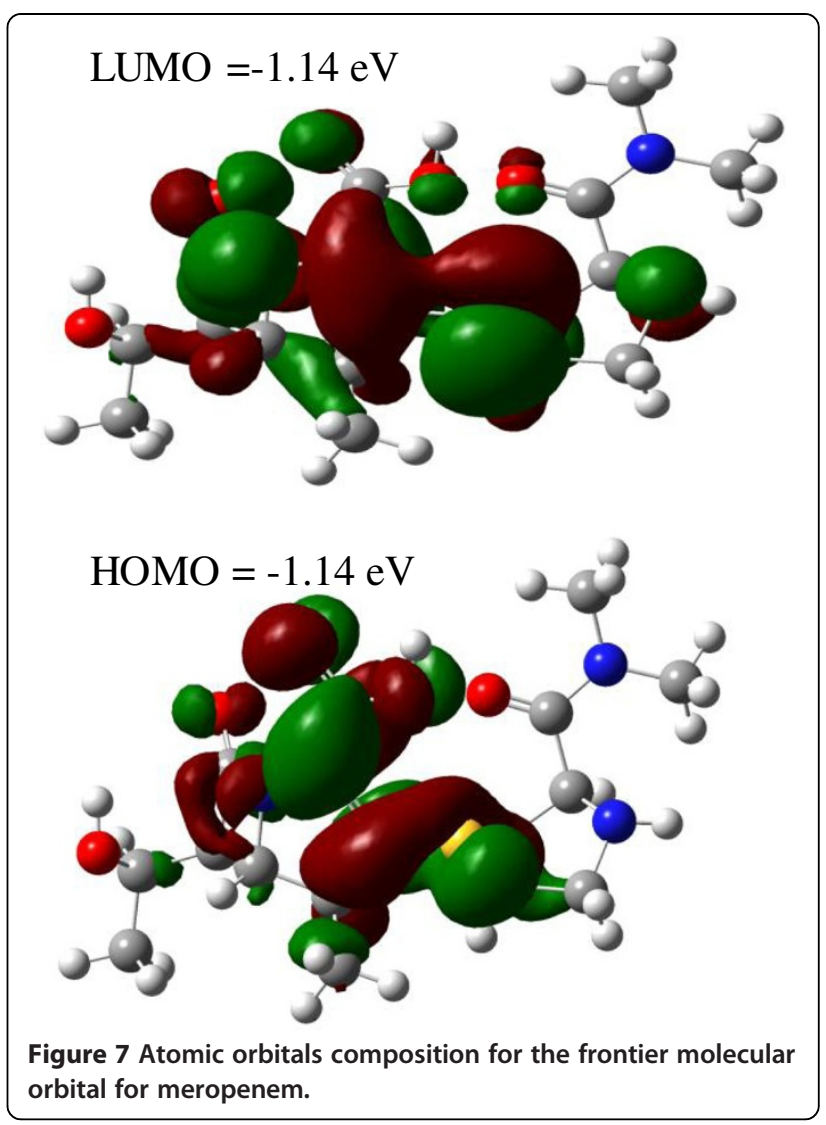

\section{Conclusions}

The proposed methods (UV, FT-IR and Raman spectroscopy) for the quality assessment of meropenem and its determination in the presence of degradation products formed during solid-state storage may be considered superior to commonly applied chromatographic techniques. The spectral and theoretical studies conducted in this work permitted evaluation of molecular changes in meropenem and characterization of the inter- and intra-molecular interactions observed during its storage

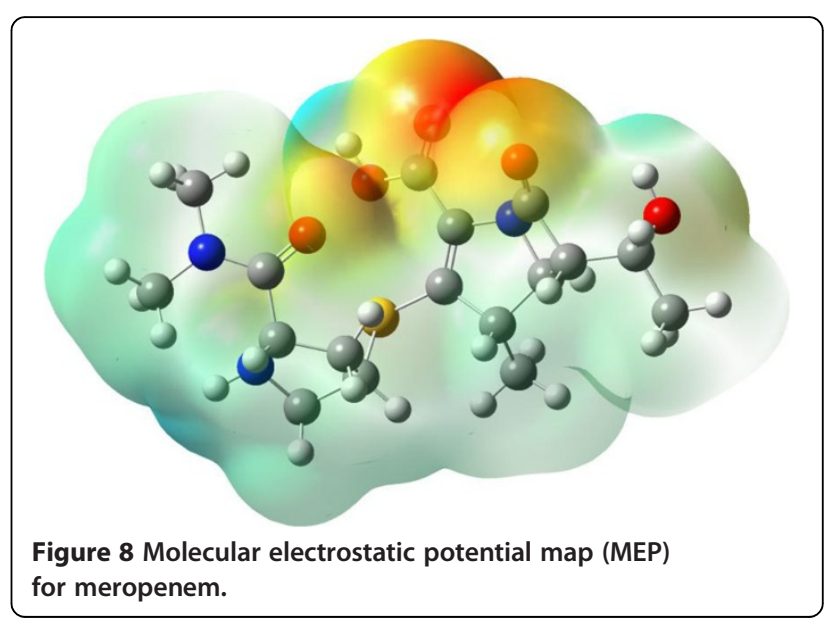


in the solid state. The analysis of the frontier molecular orbitals and the molecular electrostatic potential revealed the sites prone to electrophilic and nucleophilic attacks in meropenem.

\section{Competing interests}

The authors declare that they have no competing interests.

\section{Authors' contributions}

JCP formulated the research idea and planned the experiment, carried out characterization and interpretation results and wrote the manuscript, MP carried out UV spectra, KL prepared FT-IR and Raman spectra and interpreted them, BB carried out theoretical calculations and PZ, PG prepared the figures and tables. All the authors read and approved the final manuscript.

\section{Acknowledgements}

This study was supported by a grant from the Foundation for Polish Science (no. VENTURES/2011-8/7).

\section{Author details}

${ }^{1}$ Department of Pharmaceutical Chemistry, Faculty of Pharmacy, Poznan University of Medical Sciences, Grunwaldzka 6, Poznań 60-780, Poland. ${ }^{2}$ Department of Molecular Crystals, Institute of Molecular Physics Polish Academy of Sciences, Smoluchowskiego 17, Poznań 60-179, Poland.

Received: 13 February 2013 Accepted: 27 May 2013

Published: 8 June 2013

\section{References}

1. Nicolau DP: Carbapenems: a potent class of antibiotics. Expert Opin Pharmacother 2008, 9:23-37.

2. Hurt M, Lamb H: Meropenem: a review of its use in patients in intensive care. Drugs 2000, 59:653-680

3. Zhanel G, Wiebe R, Dialy L, Thomsaon K, Rubistein E, Hoban D, Noreddin A Karlowsky J: Comparative review of the carbapenems. Drugs 2007, 67:1027-1052

4. Edwards SJ, Emmas CE, Campbell HE: Systematic review comparing meropenem with imipenem pluscilastatin in the treatment of severe infections. Current Medical Research and Opinion 2005, 21:785-794.

5. Deshpande AD, Baheti KG, Chatterjee NR: Degradation of $\beta$-lactam antibiotics. Curr Scien 2004, 12:1684-1695.

6. Sajonz P, Wu Y, Natishan TK, McGachy NT, Tora DD: Challenges in the analytical method development and validation for an unstable active pharmaceutical ingredient. J Chrom Scien 2006, 44:132-140.

7. Markovic BD, Dobricic VD, Vladimirov SM, Cudina OS, Savic VM, KarlikkovicRajic KD: Investigation of solvolysis kinetics of New synthesized fluocinolone acetonide C-21 esters - an In vitro model for prodrug activation. Molecules 2011, 16:2658-2671.

8. Llinas A, Page MI: Intramolecular general acid catalysis in the aminolysis of beta-lactam antibiotics. Org Biomol Chem 2004, 5:651-654.

9. Cielecka-Piontek J, Michalska K, Zalewski P, Jelińska A: Recent advances in stability studies of carbapenems. Cur Pharm Anal 2011, 7:213-227.

10. Kataoka H: New trends in samples preparation for clinical and pharmaceutical analysis. Tr Anal Chem 2003, 22:232-244

11. Görög S: The changing face of pharmaceutical analysis. Tr Anal Chem 2007, 27:12-17.

12. Papp-Wallace KM, Endimiani A, Taracila MA, Bonomo RA: Carbapenems: past, present and future. Antimicrob Agents Chemother 2011, 55:4943

13. Mohr JF: Update on the efficacy and tolerability of meropenem in the treatment of serious bacterial infections. Clin Infect Dis 2008, 47:S41-S51.

14. Jones RN, Sader HS, Fritsche TR: Comparative activity of doripenem and three other carbapenems tested against Gram-negative bacilli with various $\beta$-lactamase resistance mechanisms. Diagn Microbiol Infect Dis 2005, 52:71-74.

15. Rhomberg PR, Jones RN: Contemporary activity of meropenem and comparator broad-spectrum agents: MYSTIC program report from the United States component (2005). Diagn Microbiol Infect Dis 2007 57:207-215
16. Payen MC, Wit D, Martin C, Sergysels R, Muylle I, Laethem Y, Clumeck N: Clinical use of the meropenem-clavulanate combination for extensively drug-resistant tuberculosis. Inter J Tuber Lung Dis 2012, 16:558-560.

17. Hugonnet JE, Tremblay LW, Boshoff HI, Barry CL, Blanchard JS: Meropenemclavulanate is effective against extensively drug-resistant mycobacterium tuberculosis. Science 2009, 27:1215-1218.

18. Cielecka-Piontek J, Zając M, Jelińska A: A comparison of the stability of ertapenem and meropenem in pharmaceutical preparations in solid state. J Phamraceutical Biomedical Analysis 2008, 46:52-57.

19. Mendez A, Chagastelles P, Palma E, Nardi N, Schapoval E: Thermal and alkaline stability of meropenem: degradation products and cytotoxicity. Int J Pharm 2008, 350:95-102.

20. Elragehy NA, Abdel-Moety EM, Hassan NY, Rezk MR: Stability-indicating determination of meropenem in presence of its degradation product. Talanta 2008, 77:28-32.

21. Cielecka-Piontek J, Jelińska A, Dołhań A, Zalewski P: Kinetic and thermodynamic analysis of degradation of doripenem in solid state. Inter J Chem Kinet 2012, 44:722-728.

22. Sajonz P, Vailayay A, Sudah O, McPherson L, Capodanno V, Natishan TK, Helmy R, Antia FD: Development of a gradient eluation preparative high performance liquid chromatography method for the recovery of the antibiotics ertapenem from crystallization process streams. J Chrom A 2008, 8:365-372

23. Berthoin K, Le Duff C, Marchand-Brynaert J, Carryn S, Tulkens P: Stability of meropenem and doripenem solutions for administration by continuous infusion. J Antimicrob Chemother 2010, 65:1073-1075.

24. Cielecka-Piontek J, Michalska K, Zalewski P, Zasada S: Comparative review of analytical techniques for determination of carbapenems. Cur Anal Chem 2012, 8:91-115.

25. Cielecka-Piontek J, Jelińska A: The UV-derivative spectrophotometry for the determination of doripenem in the presence of its degradation products. Acta Spectrochim A 2010, 77:554-557.

26. Cielecka-Piontek J, Lunzer A, Jelińska A: Stability-indicating derivative spectrophotometry method for the determination of biapenem in the presence of its degradation products. Cent Eur J Chem 2011, 9:35-40.

27. Validation of analytical procedures, Proceeding of the International Conference of Harmonisation (ICH), Commission of the European Communities. Geneva, Switzerland; 1996.

28. Frisch MJ, Trucks GW, Schlegel HB, Scuseria GE, Robb MA, Cheeseman JR, Montgomery JA Jr, Vreven T, Kudin KN, Burant JC, Millam JM, lyengar SS, Tomasi J, Barone V, Mennucci B, Cossi M, Scalmani G, Rega N, Petersson GA, Nakatsuji H, Hada M, Ehara M, Toyota K, Fukuda R, Hasegawa J, Ishida M, Nakajima T, Honda Y, Kitao O, Nakai H, et al: Gaussian 03, Revision B.05. Pittsburgh PA: Gaussian, Inc; 2003.

doi:10.1186/1752-153X-7-98

Cite this article as: Cielecka-Piontek et al: Solid-state stability study of meropenem - solutions based on spectrophotometric analysis.

Chemistry Central Journal 2013 7:98.

\section{Publish with ChemistryCentral and every scientist can read your work free of charge \\ "Open access provides opportunities to our colleagues in other parts of the globe, by allowing anyone to view the content free of charge." W. Jeffery Hurst, The Hershey Company. \\ - available free of charge to the entire scientific community \\ - peer reviewed and published immediately upon acceptance \\ - cited in PubMed and archived on PubMed Central \\ - yours - you keep the copyright \\ Submit your manuscript here \\ http://www.chemistrycentral.com/manuscript/<smiles>c1ccccc1</smiles> Chemistry Central}

